\title{
Pagamento por serviços ambientais: beneficios locais e globais
}

por Célia Massako Onishi, Rosana Filomena Vazoller e Bastiaan Philip Reydon

A partir dos anos 90 as iniciativas de Pagamentos por Serviços Ambientais - PSA têm se multiplicado em todo o mundo e também no Brasil, país de imenso capital natural. As perspectivas são promissoras quanto aos ganhos nos esforços de conservação, bem como em direção a uma mudança de percepção da sociedade acerca da importância dos serviços prestados pelos ecossistemas. Mas grandes são os desafios na criação dos marcos regulatórios e da estrutura de governança para a implantação das iniciativas. Os fundamentos e modalidades de PSA, além de comentários sobre experiências exitosas para a área do Saneamento, notadamente para a manutenção da qualidade dos recursos hídricos, serão alguns dos aspectos abordados nesta matéria. 
Muitos avanços institucionais, políticos e legais foram observados entre as conferências mundiais sobre o Meio Ambiente realizadas pela Organização das Nações Unidas (ONU) em Estocolmo (1972) e no Rio de Janeiro (2012), com a inclusão da temática ambiental na agenda das nações, instituições e cidadãos. Apesar dos avanços, o agravamento dos problemas ambientais persistiu, configurado atualmente em três grandes crises globais: mudanças climáticas, extinção de espécies nativas, degradação e esgotamento dos recursos hídricos (Metzger, 2007).

Tabela 1 - Categorias de serviços dos ecossistemas

\begin{tabular}{l|l}
\hline \multicolumn{1}{c|}{ Categoria } & \multicolumn{1}{c}{ Produtos ou benefícios obtidos } \\
\hline Abastecimento & $\begin{array}{l}\text { Bens ou produtos obtidos dos ecossistemas - alimen- } \\
\text { tos, água doce, madeira, fibra, outros }\end{array}$ \\
\hline Regulação / Controle & $\begin{array}{l}\text { Benefícios obtidos a partir de processos naturais - regula- } \\
\text { ção do clima, doenças, erosão, fluxo de água e polinização } \\
\text { (figura 1), proteção contra os riscos naturais, outros }\end{array}$ \\
\hline Cultural & $\begin{array}{l}\text { Benefícios não materiais obtidos dos ecossistemas } \\
\text { - recreação, valores espirituais, estéticos, paisagísti- } \\
\text { cos, patrimônio cultural, outros }\end{array}$ \\
\hline Suporte & $\begin{array}{l}\text { São os serviços necessários a todas as demais cate- } \\
\text { gorias de Serviços ecossistêmicos (SE) - ciclagem de } \\
\text { nutrientes, produção primária, formação do solo }\end{array}$ \\
\hline
\end{tabular}

Fonte: Adaptado de Millenium Ecosystem Assessment (2005)
Foi a partir das décadas 60 e 70 que os debates sobre a dicotomia entre o crescimento econômico e a preservação ambiental ocuparam o centro das atenções mundiais, devido ao aumento da degradação ambiental ocasionado pelo período de acelerada industrialização a partir do início do século XX. A destruição do capital natural - base sobre a qual se erige a prosperidade econômica-, ocorreu neste período em níveis incomparavelmente superiores em relação a toda a História anterior.

Segundo o relatório Avaliação Ecossistêmica do Milênio organi- zado pela ONU (UN, 2005; apud: UN, 2010), nos últimos 50 anos o homem introduziu drásticas modificações nos ecossistemas que resultaram na perda de biodiversidade e a redução da qualidade e quantidade de cerca de dois terços de 24 serviços ecossistêmicos. Serviços ecossistêmicos são então definidos neste relatório como os benefícios que as pessoas obtêm dos ecossistemas (um complexo dinâmico de plantas, animais e de comunidades de micro-organismos e do ambiente não vivo interagindo como uma unidade funcional), sendo agrupados em 4 principais categorias, conforme a Tabela 1.

A redução dos ecossistemas mostra diminuição de 35\% dos manguezais, $40 \%$ das florestas e $50 \%$ das áreas alagadas; $80 \%$ dos estoques de peixe e $25 \%$ da superfície terrestre devido a áreas cultivadas (Fonseca, 2010). Este cenário demonstra que os sistemas naturais estão se aproximando dos chamados "pontos de ruptura" ou "tipping point", para os quais uma perturbação adicional pode resultar em queda abrupta e irreversível dos benefícios proporcionados

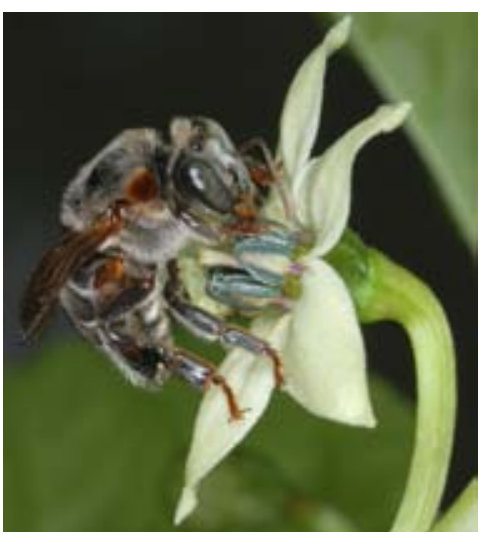

Figura1: Serviços de polinização -

Espécie Meliponafasciculata

Foto: Giorgio C. Venturieri

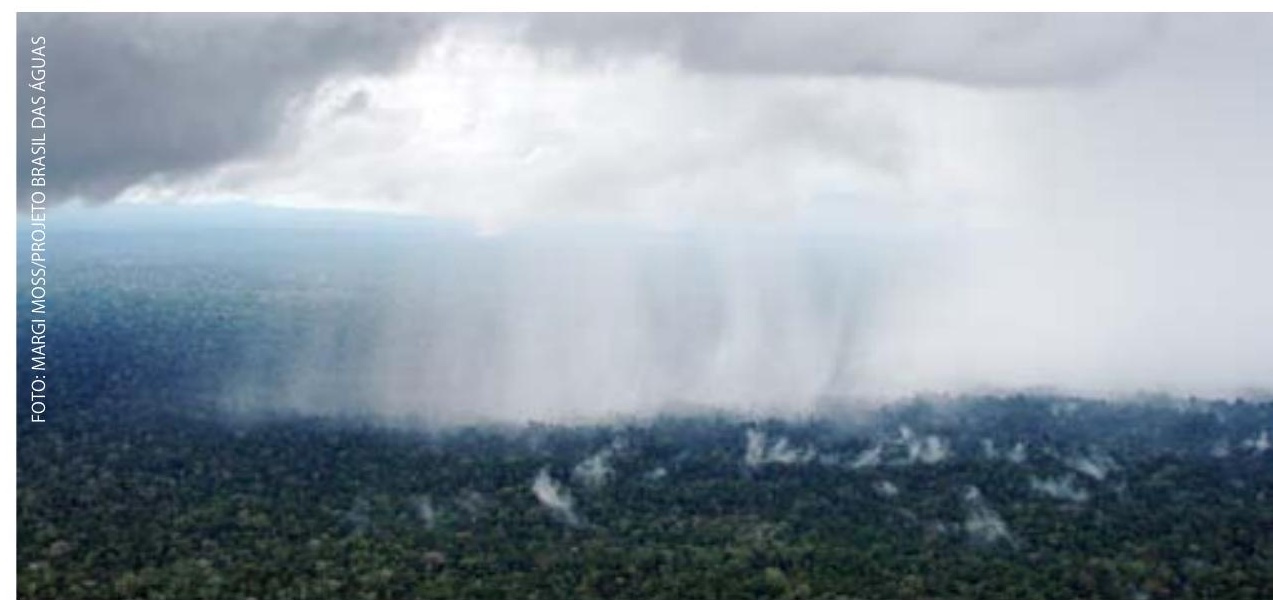

Figura 2: Formação dos rios voadores na Floresta Amazônica Fonte: Margi Moss - Projeto Brasil das Águas 


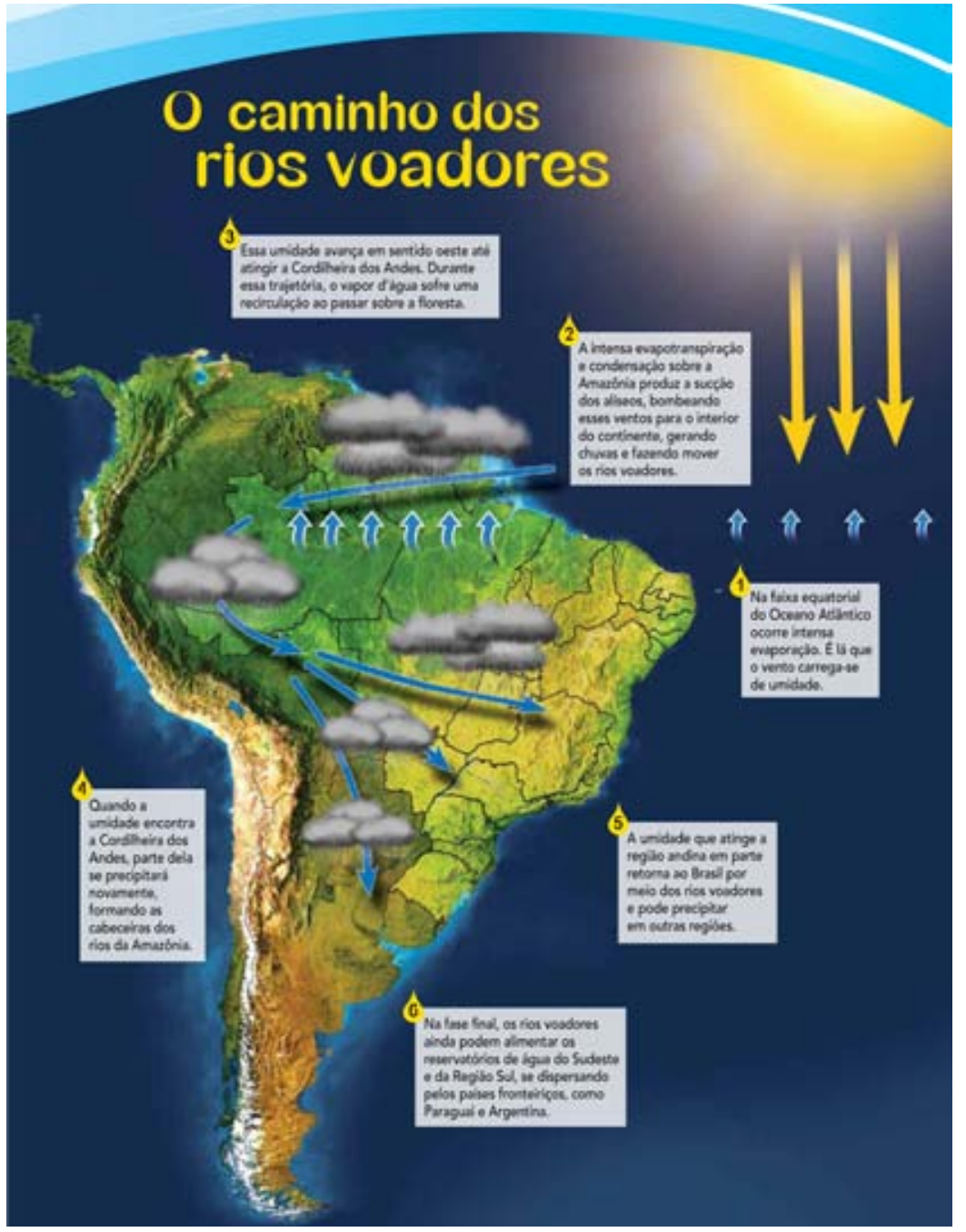

Figura 3: Formação e caminho dos rios voadores.

Fonte: Projeto Brasil das Águas - http://www.riosvoadores.com.br/o-projeto/riosvoadores

pelos ecossistemas. Os alertas da ciência vão, portanto, para além dos inevitáveis prejuízos sociais e econômicos decorrentes do quadro apresentado, mas, principalmente, sobre a real possibilidade do colapso dos sistemas naturais em função do desrespeito aos limites da natureza, em termos de sua capacidade de suporte e resiliência.

Os serviços proporcionados pelos ecossistemas ainda não são percebidos pela maior parcela da sociedade como essenciais para a manutenção do bem
2008). Sem dúvida, influencia o regime de chuvas na região centro-sul brasileira, pois parte do vapor d'água gerado na região por meio do processo de evapotranspiração junta-se às correntes de ar com umidade evaporada do oceano Atlântico, formando os chamados "rios voadores", os quais percorrem o trajeto para o Pacífico, sul e centro-sul do Brasil, Paraguai e Argentina (ver figuras 2 e 3 ). O fenômeno seria responsável por cerca de $70 \%$ das chuvas do sudeste e sul do Brasil, impactando diretamente as atividades agrícolas e a geração de energia elétrica (Andrade, 2007; MCT, 2013).

É também na Amazônia que se encontra a maior área contínua prioritária para a conservação de biodiversidade no planeta (Turner et al., 2007; apud: Wunder et al., 2008). Neste quesito o Brasil se distingue no cenário mundial por ser um dos 17 países considerados megadiversos, abrigando cerca de $20 \%$ de toda a diversidade biológica mundial conhecida em seu território, o que representa um grande potencial para a nação de geração de benefícios pelo uso sustentável desses ativos (MMA, 2013). Embora as estimativas indiquem que apenas $2 \%$ de toda a biodiversidade mundial são atualmente conhecidas. Dado o grau de magnitude desse desconhecimento, é indiscutível a observância do princípio da precaução na formulação de políticas públicas e no processo de tomada de decisão por todos os setores da sociedade em prol da conservação da biodiversidade.

Cabe destacar, nesse sentido, a necessidade primordial de investimentos na área de C,T\&I para suprir a grande lacuna no conhe- 
cimento sobre a biodiversidade, tanto no desenvolvimento de bases de dados em biodiversidade - como o organizado pelo Centro de Referência em Informação Ambiental ${ }^{1}$ de Campinas (SP), internacionalmente reconhecido-, como também na formação e manutenção de coleções biológicas, essencial para a modelagem ecológica, conforme ressalta a Profa. Dra Vera Lúcia Imperatriz-Fonseca, uma das entrevistadas ao final desta matéria.

Uma grande mudança na percepção mundial sobre a importância dos serviços provisionados pela natureza ocorreu a partir da publicação dos resultados pioneiros do economista americano Roberto Costanza no artigo $O$ valor dos serviços ecossistêmicos do mundo e do capital natural (1997). A equipe liderada por Costanza selecionou 17 serviços dos ecossistemas de 16 biomas no mundo, e chegou à estimativa de que o valor econômico dos serviços que fluem diretamente para a sociedade seria da ordem de US\$ 33 trilhões. Isto equivalia, à época, 1,8 vezes o PIB mundial de cerca de U\$ 18 trilhões.

Anteriormente, destacam-se as contribuições do economista Nicholas Georgescu-Roegen nos anos 70 para a formulação das bases da linha teórica da Economia Ecológica, que estuda as relações entre os ecossistemas e os sistemas econômicos (Costanza, 1994). Dentre as ideias revolucionárias preconizadas por Georgescu-Roegen estava a de que a Economia seria englobada pela Ecologia, afirmando ainda que o processo econômico tenderia, no futuro, ao decrescimento. Valendo-se de princípios da Termodinâmica, propôs a representação do sistema econômico como aberto e não isolado da natureza, considerando não só os recursos naturais e a energia (inputs) consumidos durante o processo produtivo, mas também os produtos e resíduos gerados (outputs) (Cechin, 2010). Embora severamente criticado e pouco aceito pelo mainstream, suas ideias sinalizavam as profundas mudanças em curso neste campo hoje.

A atual crise ambiental está intrinsecamente ligada à modificação nos processos de ocupação e uso das terras e à fragmentação de habitats nativos (Metzger, 2007). A conservação de áreas naturais é considerada uma das medidas prioritárias para o equacionamento desta crise, pelo estoque de carbono que possuem e deixa de ser emitido (Freitas e Camphora, 2009), além da proteção à biodiversidade e aos serviços de provisão de água e alimentos, entre outros. Corroboram para esta tese alguns outros fatores: o atual estágio de ineficiência ecológica dos processos produtivos quanto ao uso de recursos naturais e consumo de energia, nos EUA, por exemplo, apenas $6 \%$ do fluxo de materiais consumido vira produto (Romeiro, 2003; In: Lustosa et al., 2003); o tempo ainda requerido para a ampla difusão de inovações que promovam a diminuição da pressão sobre o uso dos recursos naturais; a impossibilidade de substituição de certos recursos naturais e serviços dos ecossistemas pelo capital e progresso técnico poupador de recursos naturais.

No entanto, a conservação concorre com as demais atividades produtivas potencialmente degradadoras, o que exige a definição de políticas ambientais específicas para a indução dos esforços de conservação ou conversão de áreas em atividades sustentáveis.

As políticas ambientais postas em prática internacionalmente têm se centrado em dois tipos de instrumentos: i) mecanismos de regulação direta, também conhecidos como instrumentos de comando e controle (ICC), na medida em que determinam uma intervenção direta sobre a ação dos agentes econômicos; ii) instrumentos econômicos (IE), que se caracterizam por mecanismos de mercado que afetam o cálculo de custos e benefícios do agente econômico em relação ao meio ambiente, influenciando suas decisões.

Os tradicionais mecanismos de comando e controle aplicados pelo Estado têm caráter punitivo, impondo-se modificações ao comportamento dos agentes degradadores, o que exige um alto dispêndio de recursos na fiscalização do cumprimento das obrigações. Os instrumentos econômicos, ou instrumentos de mercado, por outro lado, procuram internalizar os custos ambientais nas atividades econômicas como forma de influenciar os agentes responsáveis pelo dano ambiental a modificarem o padrão de uso dos recursos naturais.

A partir dos anos 90 vários

${ }^{1}$ Centro de Referência em Informação Ambiental (CRIA) - http://www.cria.org.br/ 
mecanismos baseados no mercado surgiram para a indução de ações conservacionistas, dentre eles, o chamado Pagamento por Serviços Ambientais (PSA) ${ }^{2}$, que consiste na compensação de agentes que detém algum ativo ambiental pela sua preservação.

Para os especialistas que desenvolveram os primeiros conceitos de PSA tais instrumentos poderiam ser mais eficientes na conservação das florestas e trazer resultados mais rápidos se comparados aos mecanismos de comando e controle, quando objetivam a criação de uma situação "ganha-ganha", trazendo benefícios tanto para quem garante a provisão dos serviços dos ecossistemas como para quem os demanda (Andrade, 2007). O modelo PSA complementa o modelo poluidor-pagador, dando foco ao fornecimento do serviço sob o princípio do provedor-recebedor, segundo o qual o usuário paga e o conservacionista recebe. $\mathrm{Na}$ figura 4 estão exemplificadas em um esquema básico de PSA as figuras do Comprador (Beneficiário; Governo- representando todos os usuários da sociedade) e do Provedor (Provedor-recebedor; por exemplo, o Agricultor).

A implantação do mecanismo de PSA tem como pré-condições o caráter voluntário da transação, a identificação de que ao menos um serviço ambiental esteja beneficiando algum agente interessado em garantir a manutenção de tal serviço e o esclarecimento de quem será a parte pagadora e quem será a parte recebedora. $\mathrm{Na}$ literatura sobre PSA encontram-se definições de "serviços ambientais" as atividades realizadas pelo homem que contribuem para a manutenção dos benefícios provisionados pelo ambiente (Chomitz et al., 1999; apud Wunder et al., 2008). Há também a definição de "serviço ambiental" como um dos muitos serviços prestados pelos ecossistemas (provisão de alimentos, madeira etc) e "serviços ecossistêmicos" como o conjunto dos serviços não separáveis em partes (Hercowitz e Whately, 2008).

Segundo Wunder et al. (2008) as fontes de recursos são fatores críticos na implantação de sistemas de PSA. As principais fontes de recursos para a operacionalização de esquemas de PSA seriam os Tributos (impostos, taxas e cobranças), os Acordos e Mercados (para situações em que os bens comercializados representem serviços ambientais bem definidos como o mercado de créditos de carbono). Na questão da gestão, os esquemas de PSA podem ser administrados por diversas instituições: 1) administração pública em seus diferentes níveis (federal, estadual e municipal), sendo a gestão de recursos financeiros usualmente delegada a fundos em âmbito nacional ou internacional; 2) órgãos e agências internacionais, que lideraram as experiências pioneiras em PSA e também assumindo a gestão de fundos; 3) terceiro setor, com forte atuação das ONGs internacionais. Na tabela 2 estão apresentados os mecanismos de gestão das principais fontes de recursos .

Os programas de PSA podem ser públicos ou privados e, de forma geral, englobam os serviços de captação de carbono, conservação da biodiversidade, conservação de recursos hídricos e conservação da beleza cênica (Wunder et al., 2008). Segundo Landell-Mills e Porras (2002) apud Hercowitz e Whately (2008)

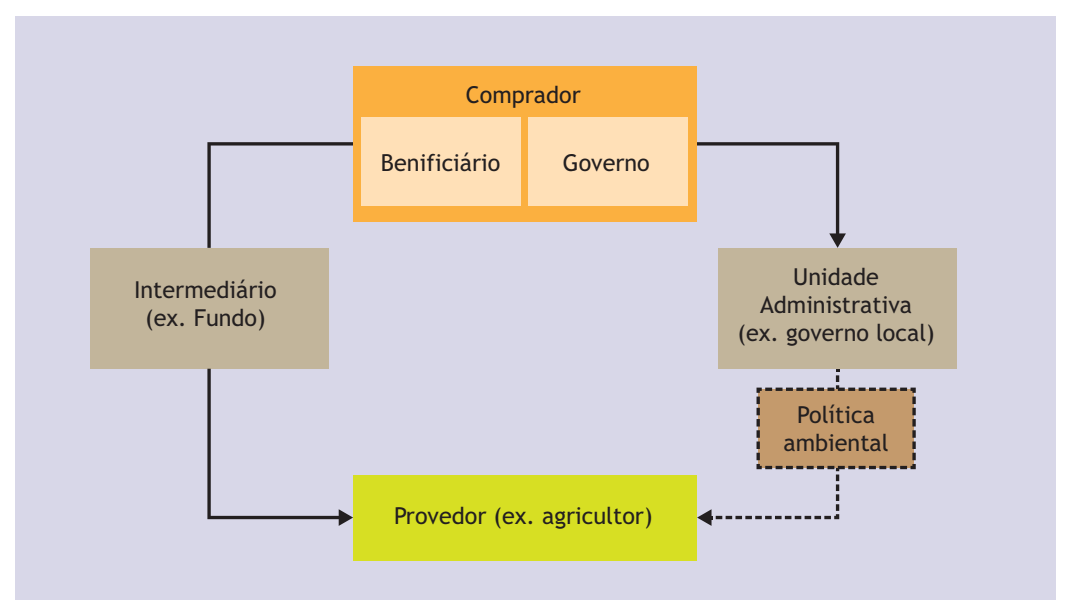

Figura 4: Exemplo de esquema básico de PSA. Fonte: Wunder et al.(2008)

\footnotetext{
${ }^{2}$ O ICMS Ecológico e o IPTU Verde são modalidades que não se enquadram na definição de PSA em sentido estrito, mas são igualmente instrumentos que promovem a conservação do meio ambiente por meio de incentivos econômicos, assim como o SNUC (Sistema Nacional de Unidades de Conservação), que traz em seu bojo vários instrumentos para a preservação e conservação das Unidades de Conservação entre eles, a compensação ambiental obrigatória nos processos de licenciamento de empreendimentos de significativo impacto ambiental negativo não-mitigável. (Geluda e Young, 2005; apud:Mattos, et al., 2009).
} 


\begin{tabular}{|c|c|c|}
\hline Funções & Categoria & Exemplos \\
\hline \multirow{5}{*}{$\begin{array}{l}\text { Fontes e } \\
\text { capta- } \\
\text { ção de } \\
\text { recursos }\end{array}$} & \multirow{3}{*}{ Tributos } & Impostos (ex: ICMS Ecológico, IPTU Verde) \\
\hline & & Cobrança (ex: cobrança pelo uso da água) \\
\hline & & $\begin{array}{l}\text { Taxas (ex: pagamento pelos custos de tra- } \\
\text { tamento público de água e de efluentes.) }\end{array}$ \\
\hline & $\begin{array}{l}\text { Acordos bi e multi- } \\
\text { laterais }\end{array}$ & $\begin{array}{l}\text { Cooperação internacional; Parcerias na- } \\
\text { cionais/internacionais; Doações, Troca de } \\
\text { títulos de dívidas }\end{array}$ \\
\hline & Mercados & Cotas e comércio (ex. mercado $\mathrm{CO}_{2}$ ) \\
\hline \multirow{4}{*}{$\begin{array}{l}\text { Gestão } \\
\text { de re- } \\
\text { cursos }\end{array}$} & $\begin{array}{l}\text { Administração } \\
\text { pública (Nacional, } \\
\text { local) }\end{array}$ & $\begin{array}{l}\text { Ministério, Secretaria do MA (Estadual, } \\
\text { Municipal) }\end{array}$ \\
\hline & $\begin{array}{l}\text { Fundos independen- } \\
\text { tes (Nacionais ou } \\
\text { internacionais) }\end{array}$ & $\begin{array}{l}\text { Fundos de Caixa, Fundos fiduciários, } \\
\text { Fundos rotativos }\end{array}$ \\
\hline & $\begin{array}{l}\text { Órgãos e Agências } \\
\text { internacionais }\end{array}$ & Vários \\
\hline & $\begin{array}{l}\text { ONG (Nacionais e } \\
\text { internacionais) }\end{array}$ & Vários \\
\hline
\end{tabular}

Tabela 2: Fontes e mecanismos de captação e gestão de recursos para PSA. Adaptado de Wunder et al. (2008)

foram documentadas cerca de 290 iniciativas de PSA, sendo o caso mais conhecido o Fonafifo da Costa Rica, país que possui um o sistema consolidado como política pública.

No Brasil, em 2012, existiam aproximadamente 180 iniciativas de PSA de acordo com Vivan (2012), englobando o mecanismo REDD (Redução de Emissões Provenientes de Desmatamento e Degradação). O mecanismo foi criado no âmbito da ONU e visa fornecer incentivos aos países em desenvolvimento via compensações aos governos, comunidades, empresas ou indivíduos que atuem na conservação das florestas em pé, modalidade para a qual o Brasil tem muito a contribuir por meio das áreas localizadas na região Amazônica (Viana, 2010). Uma das experiências mais antigas de PSA no Brasil é do Programa de Desenvolvimento Socioambiental da Produção Familiar (Proambiente), implantado na região Amazônica como política pública no início dos anos 2000 e que tem servido de referência tanto conceitual como prática para os trabalhos atuais de PSA; prevê a remuneração pelos serviços de redução de desmatamento, seqüestro de carbono, redução do risco de fogo, eliminação do uso de agrotóxicos, troca da matriz energética, conservação do solo, da água e da biodiversidade (Oliveira, 2009).

Especificamente em relação aos programas de PSA relacionados à Água (PSA Água) foram mapeados 61 casos mundiais em 2002, como apontado por Landell-Mills e Porras (2002) apud Hercowitz e Whately (2008). A experiência de maior sucesso relatada é a de Nova York, a qual empregou o esquema de PSA dentro de um amplo plano de manejo dos mananciais, com envolvimento da população. A implantação do plano de manejo garantiu a qualidade dos mananciais sem a necessidade de filtragem, a partir de um investimento aproximado de US $\$ 1,5$ bilhão em 10 anos ao invés dos US\$ 6 bilhões e mais US\$
200 a 300 milhões/ano de aporte necessários na instalação de um sistema de tratamento de água. O plano contemplava duas linhas básicas de ação, a mitigação da poluição e prevenção e redução de potenciais cargas de contaminantes futuras. A estratégia de longo prazo incluiu a aquisição de terras, promoção de incentivo aos proprietários que se dispusessem a proteger indefinidamente suas áreas, novo marco regulatório sobre mananciais e suporte financeiro para a promoção de atividades econômicas locais sustentáveis. Nesse caso, o grupo de agricultores representava um dos elementos-chave para o sucesso do plano e recebia incentivos e recursos financeiros pela implantação de planos de manejo e adoção de medidas como a preservação e recuperação de APPs. Tais iniciativas assumem importância cada vez maior considerando que 50\% da população mundial hoje se concentram em áreas urbanas (Aslam e Szczuka, 2012).

O desenvolvimento dos programas de PSA de base florestal (PSA Carbono) no Brasil leva em conta que uma das principais causas da perda dos biomas terrestres, especialmente na floresta Amazônica, consiste na expansão das fronteiras da atividade agropecuária. Os setores de mudança no uso da terra e florestas e o da agricultura são responsáveis, respectivamente, por $61 \%$ e $19 \%$ das emissões de gases de efeito estufa nacionais (Brasil, 2013); $75 \%$ das emissões nacionais são provenientes do desmatamento da Amazônia (Mattos et al., 2009).

Embora o desmatamento da floresta seja um fenômeno determinado por múltiplos fatores, dois problemas são, de forma combinada, os principais: a especulação com terras por meio do 
próprio desmatamento- que em alguns casos como no Estado do Acre chega a multiplicar em 14 vezes o valor da terra, após convertida em terra produtiva para a atividade pecuária - e a ausência de uma governança fundiária. Portanto, previamente ao estabelecimento de um sistema de PSA é fundamental que o Estado brasileiro assuma a efetiva governança sobre a propriedade da terra (regulação e titulação). A insegurança associada à propriedade da terra continua sendo um grande problema principalmente na região Amazônica e afeta a implantação de programas de PSA. Na ausência da titulação da terra e conseqüentemente o proprietário, não há como destinar os valores referentes à operacionalização de um PSA. Associa-se a isto o fato de que parcela significativa das terras da região Amazônica (42\%) seja devoluta (Shiki, 2007; apud Reydon, 2011) e na medida em que não são apossadas ou tituladas estão passíveis de serem apropriadas privadamente. O PSA da floresta pode então estimular a posse e ocupação para a obtenção futura do benefício, gerando conflitos pelas terras. Em relação aos valores médios pagos por ano como compensação ao não-desmatamento no sistema de PSA, estes devem cobrir os custos de oportunidade da atividade agropecuária por hectare (Reydon, 2011).
A existência de um adequado marco regulatório é fundamental para o êxito da implantação e manutenção de sistemas de PSA, prevendo mecanismos para a garantia de repasse dos recursos aos agentes que protegem os serviços dos ecossistemas e o arranjo institucional para a governança dos sistemas. No Brasil havia 28 propostas legislativas sobre PSA até maio de 2012 - entre leis, decretos e projetos de lei -, incluindo as relacionadas à temática do clima, conforme levantamento de Santos et al. (2012). Dentre as propostas está o projeto de Lei 792/2007 em tramitação no Congresso Nacional, que institui a Política Nacional de Pagamento por Serviços Ambientais (PNPSA), que destaca o Programa Federal de Pagamento por Serviços Ambientais (ProPSA) e estabelece formas de controle e financiamento por meio da criação do Fundo Federal de Pagamento por Serviços Ambientais (FunPSA) e do Cadastro Nacional de Pagamento por Serviços Ambientais. São contemplados pela proposta diferentes tipos de serviços nas categorias de provisão, suporte, regulação e culturais. A operacionalização do programa prevê o funcionamento de duas instâncias de gestão: Comitê colegiado (gestão do programa) e Instituição bancária (gestão financeira), conforme a figura 5 . A fonte dos recursos poderá ter origem em fluxos da União, agentes privados ou recursos do fundo a ser criado (FunPSA) ${ }^{3}$, formado, entre outros, por recursos da cadeia do petróleo (até 40\% do montante que cabe à MMA).

A novidade da proposta reside no amplo rol de beneficiários previstos, incluindo estados e municípios, pessoas físicas ou jurídicas de direito público ou privado e grupo familiar ou comunitário. É amplo também o critério de elegibilidade dos projetos, pois as atividades de proteção aos ecossistemas poderão ocorrer em áreas protegidas por lei públicas ou privadas, como APPs, RLs, Unidades de Conservação e Terras Indígenas, entre outros. O acesso aos recursos do ProPSA se dará mediante o atendimento dos requisitos de enquadramento em uma das prioridades definidas pelo projeto de lei ${ }^{4}$, além da comprovação do uso ou ocupação regular do imóvel e adesão formal por meio de assinatura de termo específico. Estão previstos mecanismos de verificação e monitoramento do programa e validação/certificação quanto ao serviço prestado, sendo esta realizada provavelmente por entidade técnico-científica independente. A avaliação do programa será feita pelo órgão colegiado, decorridos quatro anos de sua implementação.

Além das propostas legislativas sobre PSA relacionadas predominantemente ao meio rural e

\footnotetext{
${ }^{3}$ Este fundo seria "formado por: i) recursos da cadeia do petróleo (até 40\% do montante que cabe à MMA); ii) dotações consignadas na Lei Orçamentária Anual da União e em seus créditos adicionais; iii) recursos decorrentes de acordos, ajustes, contratos e convênios celebrados com órgãos e entidades da administração pública federal, estadual, do Distrito Federal ou municipal; iv) doações realizadas por pessoas físicas ou por entidades nacionais e internacionais, públicas ou privadas; v) empréstimos de instituições financeiras nacionais ou internacionais; vi) reversão dos saldos anuais não aplicados; e vii) rendimentos que venham a auferir como remuneração decorrente de aplicação do seu patrimônio" (Santos et al., 2012).

${ }^{4}$ Prioridades citadas no PL 792/2007: "i) a conservação e melhoramento dos recursos hídricos; ii) a conservação e preservação da vegetação nativa, da vida silvestre e do ambiente natural em áreas de elevada diversidade biológica; iii) conservação, recuperação ou preservação das Unidades de Conservação e Terras Indígenas; iv) recuperação e conservação dos solos e recomposição da cobertura vegetal de áreas degradadas, por meio do plantio exclusivo de espécies nativas ou em sistema agroflorestal; e v) captura e retenção de carbono nos solos por meio da adoção de práticas sustentáveis de manejo de sistemas agrícolas, agroflorestais e silvipastoris” (Santos et. al., 2012).
} 
Figura 5: Estrutura de governança do ProPSA. Fonte: (Santos et al., 2012)

às áreas de mata nativa, existem estudos para a elaboração da Política Nacional de Pagamento por Serviços Ambientais Urbanos (Psau), que traz os conceitos de PSA aplicados ao contexto urbano. Os serviços ambientais urbanos seriam definidos como as "atividades realizadas no meio urbano que gerem externalidades ambientais positivas, ou minimizem externalidades ambientais negativas, sob o ponto de vista da gestão dos recursos naturais, da redução de riscos ou da potencialização de serviços ecossistêmicos, e assim corrijam, mesmo que parcialmente, falhas do mercado relacionadas ao meio ambiente" (IPEA, 2010). A atividade de reciclagem seria um dos exemplos contemplados nesta proposta. $\mathrm{O}$ pagamento por serviços ambientais relacionados à questão dos resíduos sólidos está prevista no Artigo 80, inciso VI do Decreto no. 7.404 de 23.12.2010, que regulamenta a Lei no 12.305 , de 2.08.2010 que institui a Política Nacional de Resíduos Sólidos.

Finalmente, expectativas otimistas cercam a implantação dos sistemas de PSA, dado o seu potencial para a indução de mudanças de atitudes dos agentes envolvidos em direção a práticas sustentáveis. Além disso, este instrumento confere materialidade e operacionalidade a abstratos conceitos como "Sustentabilidade" ao definir claramente o bem ambiental protegido, atores e mecanismos de repasse.

No entanto, há que se ressaltar a necessidade de que tal instrumento deve ser implantado em conjunto com outros mecanismos de comando e controle, para que os esforços de proteção de áreas e serviços dos ecossistemas sejam efetivos no longo prazo. O Zoneamento Ecológico Econômico (ZEE), que eleva o custo de oportunidade da não-preservação em determinadas áreas seria um desses complementos. Outras ações envolvendo esforços para o aumento da produtividade também devem ser implementadas para evitar os chamados "vazamentos" (leakage) do desmatamento para outras áreas, ou seja, o proprietário reserva uma área preservada para recebimento do PSA e outra para manter a atividade pecuária, sem a necessidade de preservação (Andrade, 2007).

Há críticas também quanto aos riscos de que os sistemas de PSA envolvendo o desmatamento evitado se transformem em mero mecanismo de transferência de renda, sem que os recursos entrem na economia como investimento no sistema produtivo, ocasionando um efeito perverso ao desenvolvimento econômico local (Costa, 2007; apud Mattos et al., 2009). É necessário, portanto, que a política nacional de serviços ambientais esteja atrelada à política nacional de meio ambiente, dentro de um plano macro de desenvolvimento para a nação (Mattos e Hercowitz, 2009).

A Revista DAE procurou a opinião de representantes dos setores da Academia, Público/ Legislativo e Terceiro Setor que estão relacionados à temática do Pagamento por Serviços Ambientais, dada as suas múltiplas facetas e por estar ainda em fase de consolidação, inclusive conceitual, no mundo todo.

Foram entrevistados a Profa. Dra. Vera Lúcia Imperatriz Fonseca, Bióloga, professora da Universidade de São Paulo (USP) e coordenadora do Grupo de Pesquisa Serviços de Ecossistemas do Instituto de Estudos Avançados da USP (IEA-USP), que destaca o papel fundamental da Educação para suprir as lacunas no conhecimento acerca do tema dos serviços dos ecossistemas, especialmente quanto ao cumprimento das Metas de Aichi pelos países signatários da Convenção da Biodiversidade (CDB), pelas quais se definem caminhos para garantir a proteção à biodiversidade (Brasil, 2010); o Deputado Arnaldo Jardim como relator do Projeto de Lei 792/2007 aborda os desafios para garantir um processo participativo para que a lei seja efetivamente internalizada pela sociedade; Carlos Krieck, Biólogo e Assessor para Serviços Ambientais e Biodiversidade do Vitae Civilis Instituto para o Desenvolvimento, Meio Ambiente e Paz, que traz o balanço da atual situação de implantação de programas de PSA no Brasil e no mundo, a partir da análise dos resultados do IV Congresso Internacional de Pagamentos Por Serviços Ambientais realizada no Brasil em novembro de 2012. 


\section{Entrevistas}

\section{Vera Lúcia Imperatriz-Fonseca}

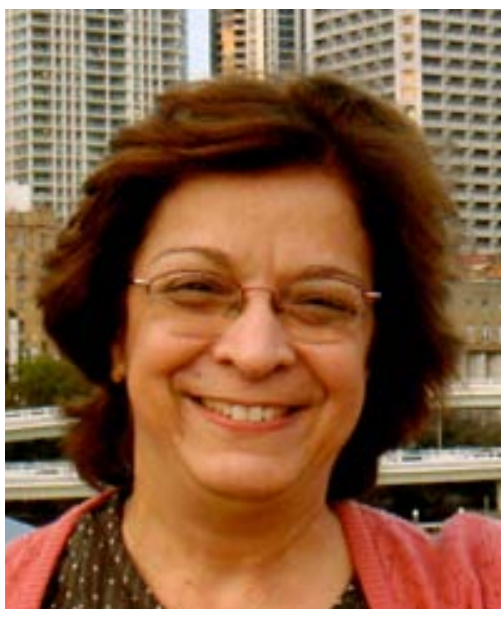

1. Segundo o economista indiano Pavan Sukhdev, coordenador do estudo The Economics of Ecosystems and Biodiversity (TEEB), o cenário de "invisibilidade" econômica da natureza seria uma das causas da desvalorização e destruição do capital natural. Os estudos de valoração dos serviços ambientais têm contribuído para mudanças nesse sentido?

O conceito dos serviços de ecossistemas surgiu nos anos 80, quando os ecólogos chamaram a atenção para natureza dos recursos naturais, insubstituíveis, e que precisavam ser usados com cuidados pela crescente população humana. No início da década de 90 surge o conceito de capital natural e logo em seguida a necessidade de uma valoração global dos recursos naturais (Costanza et al, 1997). Nesta ocasião, a demanda de um maior conhecimento ecológico sobre o manejo dos recursos naturais e o que significam no modelo da economia ambiental incentivaram o desenvolvimento de uma ciência integradora e análises de custo benefício. Nos anos 2000, o Millennium Ecosystem Assessment evidenciou um panorama global de perda de biodiversidade e da importância dos serviços ecossistêmicos como o ponto de atuação que transmitia valores científicos de modo objetivo aos tomadores de decisão. O crescimento rápido da população e externalidades como as alterações globais contribuíram para que esta abordagem fosse aceita.

Avaliações globais do estado de comprometimento dos recursos naturais foram apresentadas em 2009 e no ano Internacional da Biodiversidade, 2010. Em 2012 foi criado pela ONU o IPBES, que é o Painel Internacional de Biodiversidade e serviços de ecossistemas, e que deverá funcionar como o IPCC. O pagamento pelos serviços ambientais foi abordado de dois modos diferentes no início da utilização deste conceito.

A abordagem da economia ambiental para o pagamento destes serviços tentou moldar os serviços ecossistêmicos no modelo do Mercado, com ênfase na eficiência.

A abordagem da economia ecológica tentou moldar as instituições econômicas às características físicas dos serviços dos ecossistemas, priorizando a sustentabilidade ecológica e a distribuição justa e requerendo uma abordagem multidiscipli- nar (Farley \& Costanza, 2010).

A Declaração de Heredia sobre os pagamentos dos serviços dos ecossistemas recomendou as diretrizes a serem utilizadas para esta finalidade. De um modo geral, entretanto, os conceitos de capital natural, serviços ecossistêmicos, biodiversidade e pagamento por estes serviços não são conhecidos pela maior parte da população brasileira. O grande dilema entre a distribuição de áreas para a conservação ambiental e a agricultura no Brasil ilustram bem este problema.

Convém lembrar também que cerca de 2 bilhões de pessoas, da população atual de 7 bilhões de habitantes da Terra, vivem exclusivamente da exploração destes recursos, que são finitos.

2. Os mecanismos de pagamento por serviços ambientais seriam instrumentos eficazes para a reversão do agravamento da crise ambiental?

Seriam instrumentos eficazes. A valoração recente dos serviços da polinização e sua importância econômica (em média $10 \%$ do valor do rendimento das culturas globais) têm promovido estudos mais profundos e metanálises necessárias para a tomada de decisão na questão da segurança alimentar, por exemplo.

A conscientização de que a perda da biodiversidade é irreparável também do ponto de vista econômico e dos problemas causados pela utilização excessiva dos serviços ecossis- 
têmicos no antropoceno ${ }^{5}$ é fundamental para as formulações de políticas públicas.

\section{Do ponto de vista científico quais seriam os atuais avanços e lacunas no conhecimento relacionado aos serviços dos ecossistemas?}

Os avanços são relacionados à discussão do tema em algumas áreas políticas e empresariais, mas ainda de modo muito tímido considerando-se o quadro global.

Lacunas:

- Planejamento ambiental e a gestão baseada nos serviços dos ecossistemas, que já ocorre em países como a Grã Bretanha, é um modelo muito bom.

- Precisamos trabalhar mais com os conceitos de resiliência dos ecossistemas, (ou seja, não permitir que a degradação seja tão grande que o ecossistema não possa voltar ao estado original cessada a perturbação), também nas decisões políticas.

- Uma grande lacuna vem com a falta de conhecimento sobre biodiversidade de grande parte do país, e da falta de incentivo para a formação e implementação de coleções biológicas regionais e digitalização dos acervos existentes, incompatível com a importância do país megadiverso. A modelagem ecológica é uma ferramenta eficaz, mas necessita do livre acesso aos acervos das coleções biológicas, inexistentes para grande parte dos nossos ecossistemas.

- Não temos no Brasil políticas públicas e dotação orçamentária para enfrentar as consequências ambientais e sociais do aquecimento global, que já pode ser constatado em todo país, e clama por projetos de restauração.

- Educação em todos os níveis sobre os conceitos de biodiversidade e aplicação das metas de Aichi $^{6}$.

Vera Lúcia Imperatriz Fonseca é Bióloga, professora da Universidade de São Paulo (USP), coordenadora do Grupo de Pesquisa Serviços de Ecossistemas do Instituto de Estudos Avançados da USP (IEA-USP) e professora visitante sênior da CAPES na Universidade Federal Rural do Semi-Árido (UFERSA), no Rio Grande do Norte (RN).

\section{Arnaldo Jardim}

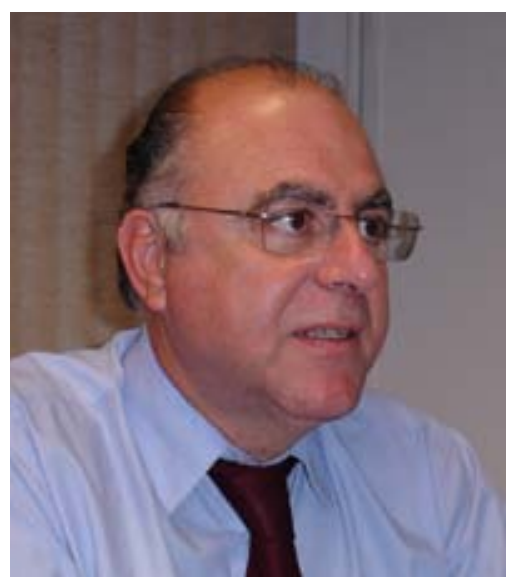

1. Qual é o atual estágio de tramitação do PL e os principais de- safios para a sua implantação?

Na organização do Projeto de lei $n^{\circ}$ 792/2007 sobre Pagamento por Serviços Ambientais (PSA), procuramos que o processo seja o mais interativo possível. Quando se faz uma legislação e essa fica artificial, passa a haver uma dificuldade imensa de fazer com que seja cumprida.

Uma legislação não pode ser somente um retrato da realidade, porque ela vira conservadora, e não pode ser só a nossa Utopia, porque ela se torna irrealizável. O desafio do legislador é sempre achar um ponto de equilíbrio para ir além, sinalizar mudanças culturais, comportamentais, mas de uma forma em que se tenha claro também o caminho a percorrer. Nós temos um problema na nossa legislação ambiental, ela é mandatária, mas em muitas vezes não estabelece os instrumentos necessários. Voltarei a uma experiência recente sobre a Política Nacional de Resíduos. O projeto estava parado há 19 anos e muitos tentaram aprová-la, sem sucesso. Nós conseguimos a aprovação ao transformar o que era divergência em consenso. Construído à custa de muita conversa, de muito apro-

\footnotetext{
${ }^{5}$ Antropoceno - Definição proposta pelos cientistas para classificar o atual momento do planeta como uma nova época geológica moldada pelo ser humano, caracterizada pelas mudanças climáticas, a acidificação dos oceanos, a erosão dos solos e as ameaças à biodiversidade Fonte: http://www.iea.usp.br/iea/boletim/contato168.html

${ }^{6}$ As Metas de Aichi foram estabelecidas na COP 10 da Convenção sobre Diversidade Biológica (CDB) em 2010 pelos 193 países-membros, na cidade de Nagoya, capital da província de Aichi, Japão. Fonte: http://www.mma.gov.br/informma/item/8605-o-conabio-e-as-metas-de-aichi
} 
fundamento, de um trabalho de despartidarização do debate em direção a uma política pública estável que tinha que transcender o governo e gerar orientações perenes. Faltou alguma coisa? Faltou. Faltaram instrumentos econômicos, incentivos tributários, fiscais, que estão colocados de uma forma genérica na lei, sem propor diretamente os mecanismos, tão afirmativo quanto desejaria, mas na negociação não conseguimos fazer prevalecer. Esta experiência conduz à questão do PSA.

Após todos esses desafios da nova legislação, e particularmente da polêmica em torno da questão do Código Florestal, fica claro que precisamos de instrumentos que compensem, que premiem, que reconheçam diferentes expressões, mas que dizem a mesma coisa: você tem que saudar, valorar e pagar por quem presta Serviços Ambientais.

A respeito do PSA, o processo de formulação da legislação é muito estimulante, é inédito porque constrói novos conceitos ou faz reorientar conceitos antigos. A tramitação na Câmara já tem um certo tempo e essas mudanças de relatores que ocorreram foram mudanças positivas, porque, num determinado instante, passou na Comissão do Meio Ambiente. Depois passamos na Comissão da Agricultura e se conseguiu se construir um consenso lá. Atualmente a PL 792/2007 está na Comissão de Finanças e Tributação, onde fui designado relator da matéria.

Demos um passo importante recentemente, no dia 02 de abril realizamos uma audiência pública no âmbito da Comissão Mista Permanente do Congresso Nacional sobre Mudanças Climáticas. Pude destacar que o PSA insere-se entre os instrumentos de valoração econômica da biodiversidade e de desenvolvimento da chamada economia verde. Sem dúvida, é uma estratégia complementar à legislação de comando e controle, de estímulo à implantação das ações de conservação.Além disso, o PSA incorpora o princípio do "protetor-recebedor", ou seja, os que promovem ações direcionadas à conservação, em especial as atividades de restauração de ecossistemas degradados, devem ser ressarcidos financeiramente por essa atividade.As experiências de pagamento por serviços ambientais, vêm sendo desenvolvidas pela ANA (Agência Nacional de Águas) em bacias críticas em relação à disponibilidade de recursos hídricos, em cidades localizadas nos estados de São Paulo, Minas Gerais, Paraná, Espírito Santo, Rio e Janeiro e Santa Catarina.

A matéria é complexa e, no plano nacional, constitui um vácuo legislativo no Brasil e tem

\section{Carlos Augusto Krieck}

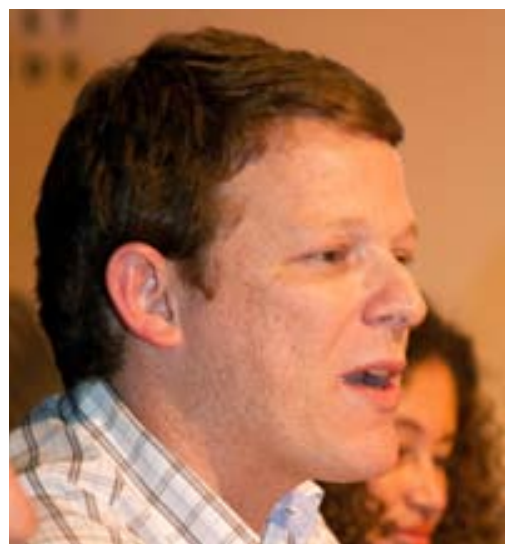

1. Quais foram as principais sínteses e conclusões resultantes do IV Congresso Internacional de Pagamentos Por Serviços Ambientais realizado em 2012 exigido intensos debates no Congresso Nacional, bem como no âmbito da Sociedade Civil Organizada.Portanto, trabalhamos para a aprovação da nova lei, que será um grande avanço na gestão ambiental brasileira, pois se leis ambientais punem aqueles que degradam o meio ambiente, enquanto que a política de PSA incentiva positivamente a adoção de comportamentos ambientalmente adequados e beneficia quem promove a conservação e respeita os direitos das gerações futuras.

Arnaldo Jardim. Engenheiro Civil pela Escola Politécnica da USP. Deputado Federal pelo PPS e relator do Projeto de Lei 792/2007 em tramitação no Congresso Nacional, que institui a Política Nacional de Pagamento por Serviços Ambientais (PNPSA). quanto ao atual cenário da implantação de programas de PSA no Brasil e no mundo?

O IV Congresso Internacional de Pagamento por Serviços Ambientais teve como tema principal "Avaliação de Impacto e Monitoramento Socioeconômico Ambiental" buscando discutir principalmente os resultados das iniciativas de PSA em andamento e suas lições aprendidas. No Brasil percebe-se um aumento significativo no interesse pelo tema PSA e isso é refletido no grande aumento do número de iniciativas em todas as regiões do Brasil. Os primeiros projetos de PSA implantados no Brasil tiveram seu início 
em 2005 e 2006, com a criação dos projetos: Oásis - São Paulo (São Paulo-SP), Conservador das Águas (Extrema-MG) e Ecocrédito (Montes Claros-MG). A partir da implantação dessas 3 iniciativas em campo com os primeiros pagamentos, muitos outros projetos foram sendo criados. Esse crescimento é comprovado pelo estudo liderado pelo Ministério do Meio Ambiente (MMA) através do Diálogo Setorial Brasil-União Européia sobre PSA onde foram registrados em 2012 aproximadamente 180 iniciativas que se denominam PSA em todo o país. Porém, apesar do interesse pelo tema e aumento do número de projetos no Brasil, os debates durante o congresso mostram que são poucos os projetos que estão na etapa de implantação, ou seja, com os contratos e pagamentos em andamento e esses, tem dificuldades de sistematizar seus resultados e monitorar seus impactos. Mas isso não deve ser visto de maneira negativa, pelo contrário, é um processo natural de aprendizado e que para se fortalecer e ganhar escala, depende da criação de políticas públicas e engajamento dos usuários-pagadores dos serviços ambientais.

Em outros países da América Latina, como Costa Rica e México, por exemplo, essas dificuldades iniciais já foram superadas e seus Programas Federais e Estaduais estão sendo ampliados e expandidos. Mas isso só está sendo possível, graças ao processo transparente de monitoramento dos resultados e avaliação dos impactos ambientais, sociais e econômicos dos programas, demonstrando para toda a sociedade que o investimento realizado em PSA tem retorno substancial para a população. Nesses casos, os serviços ambientais não são vistos como algo abstrato e de responsabilidade apenas de pesquisadores e ambientalistas, mas sim, como algo essencial para a manutenção e melhoria da qualidade de vida de todos.

2. Como a questão da "Adicionalidade" tem sido abordada nas discussões acerca da implantação dos programas de PSA?

A adicionalidade tem sido motivo de profundos debates entre os diversos setores da sociedade no Brasil não só pela questão conceitual e metodológica do PSA, mas também por conta das últimas alterações no Código Florestal brasileiro e do trâmite do PL 792/2007 que institui a Política Nacional de PSA. O ponto de entrave nessa discussão é que quando discutimos PSA de maneira geral, estamos falando de diferentes serviços ambientais como água, carbono, biodiversidade, beleza cênica, dentre outros, que tem suas especificidades e que algumas vezes, precisam ser discutidos de forma separada, incluindo a questão de adicionalidade.

Esse conceito surge com os projetos de carbono fomentados pelo Protocolo de Kyoto, sendo a adicionalidade pré-requisito básico para que um projeto seja levado adiante. Mas aqui estamos falando de projetos de grande escala que terão créditos de carbono negociados na bolsa de valores, de interesse de grandes empresas e dos governos de diversos países do mundo. Isso é muito diferente de um projeto de PSA com foco em pequenos e médios proprietários rurais de uma ou duas bacias hidrográficas, que é a maioria dos casos hoje no Brasil. Além de considerarmos a questão de escala nessa discussão sobre adicionalidade, há de ser considerados também os diferentes serviços negociados. Quando falamos de PSA-Água, por exemplo, a adicionalidade tem um sentido, enquanto que se estivermos discutindo um PSA-Biodiversidade a adicionalidade pode ter outro significado/interpretação totalmente diferente. Se uma determinada prefeitura ou organização não-governamental identifica uma bacia hidrográfica potencial para implementação de um PSA com o objetivo de manter as florestas já existentes para conservar a biodiversidade existente e evitar o carreamento de sedimentos para um córrego, rio ou nascente, não necessariamente deve ser comprovada adicionalidade, mas sim, a manutenção da área fornecedora de serviços ambientais. Nesses casos, a recuperação de áreas degradadas (que aqui são minoria) é algo que é desejável, mas não essencial a implantação do projeto. Além disso, estamos falando de um espaço de tempo determinado. Projetos de PSA utilizam contratos de 1

\footnotetext{
${ }^{7}$ Adicionalidade - "Critério estabelecido pelo artigo 12 do Protocolo de Quioto, ao qual estão submetidos os projetos desenvolvidos através do Mecanismo de Desenvolvimento Limpo. Sob este critério, uma atividade deve, comprovadamente, resultar na redução de emissões de Gases de Efeito Estufa ou no aumento de remoções de CO2 de forma adicional ao que ocorreria na ausência de uma atividade de projeto. Tal critério tem como objetivo avaliar se a atividade proporciona uma redução real, mensurável e de longo prazo para a mitigação das mudanças climáticas". Fonte: http://www.ipam.org.br/saiba-mais/glossariotermo/Adicionalidade/2
} 
a 30 anos, sendo que a maioria está utilizando contratos de 4 a 5 anos. Como comprovar adicionalidade em um espaço de tempo tão curto?

E aqui neste ponto entramos num ponto importantíssimo da discussão. Se adicionalidade é algo considerado como pré-requisito, os principais proprietários rurais a serem contratados em um determinado projeto serão os que desmataram e não cumpriram a lei florestal até hoje, enquanto que os proprietários rurais que cumpriram a lei e que muitas vezes fizeram mais do que a lei exigia, são desconsiderados ou deixados de lado, gerando incentivos perversos. Em uma visita ao projeto Oásis-Apucarana (Apucarana-PR) um proprietário rural falou: "até hoje só se via incentivos, acesso a crédito e projetos, para aqueles que desmataram e precisavam recuperar suas áreas. Com o PSA finalmente eu que sempre protegi a floresta e minhas nascentes sou premiado e reconhecido". Esse proprietário é modelo no projeto e um dos que recebe o maior pagamento pelos serviços ambientais prestados.

Com isso, acreditamos que cada caso deve ser tratado com cuidado e que o conceito de adicionalidade deve ser considerado com cautela nos projetos de PSA. Dificilmente teremos uma regra geral para todos os projetos, mas acreditamos que no Brasil hoje já existem diversos cases de sucesso que devem servir de exemplo para os projetos que estão na sua fase de planejamento e que um dos pontos fundamentais nessa fase de planejamento é proporcionar a participação de todos principalmente dos menos favorecidos economicamente e socialmente, acreditando ainda, que a premia- ção ou pagamentos pelos serviços ambientas prestados, podem se dar através de compensações e acesso a serviços de interesse da comunidade envolvida.

3. Os PSA são, por definição, voluntários. Há algum fundamento na preocupação manifestada por alguns setores da sociedade (usuários dos serviços ambientais) de que se tornem obrigatórios?

Essa é uma preocupação unicamente do setor privado, com medo que o PSA se torne mais um "imposto" a pagar. Nesse sentido, acreditamos que empresas de energia e eletricidade, por exemplo, devem sim reconhecer os produtores rurais que fornecem a matéria-prima ou serviço que essas empresas utilizam ou revendem. Hoje, por exemplo, uma empresa como a Sabesp retira a água para tratamento e abastecimento da população de graça. Além disso, esse trabalho com os proprietários rurais através do PSA, pode ser um investimento estratégico para a empresa, que além de ganhar aliados, terá uma quantidade e qualidade de água disponível muito melhor do que inicialmente. É um investimento no seu próprio negócio e não mais um imposto. Isso só é realidade se o pagador for de outra região e, de fato, não tiver nada a ver com a área do projeto. Um case que exemplifica isso, é o da Saneatins que abastece Palmas (TO). Os dados de monitoramento deles indicam que nos últimos 20 anos eles perderam aproximadamente $80 \%$ do volume de água na sua área de captação, basicamente devido ao desmatamento e ocupação irregular das beiradas de rio para agricultura de subsistência. Realizaram estudo e para captar água do lago existente na cidade sairia muito mais caro do que realizar um trabalho de PSA com esses proprietários da bacia que eles utilizam para captação, através de um PSA.

4. Há especialistas que avaliam os mecanismos de PSA como soluções temporárias para a preservação dos ecossistemas e dos seus serviços. Qual é a sua opinião?

Os últimos estudos e publicações referentes a projetos já estabelecidos na América Latina e no Brasil evidenciam alguns pontos importantes a serem considerados nessa questão. $\mathrm{O}$ primeiro ponto e a chave para o sucesso de um PSA é a simplicidade no seu planejamento e execução. Isso significa que todas as fases do projeto devem estar muito bem embasadas, mas que devem primar pela simplicidade na metodologia de campo e monitoramento, não só para reduzir custos de transação, mas também para que os proprietários envolvidos possam entender claramente $\mathrm{o}$ que está sendo negociado, por quanto está sendo negociado e como isso será monitorado durante todo o projeto. Além de evitar altos custos com consultores e infinitas horas de campo na fase de diagnóstico, engaja o proprietário contratado que se sente parte do projeto e não apenas um recebedor de uma bolsa ou auxílio do governo.

Outro ponto importante é ter muito claro qual o objetivo da iniciativa de PSA que está sendo iniciada. Para que o PSA tenha resultados concretos é importante ter clareza de qual é o problema que queremos resolver e o que queremos mudar. Esse é um dos pontos fracos dos projetos que conhecemos no Brasil. A grande maioria dos projetos surgem de uma ou mais entidades que planejam todo o projeto 
e chegam para os proprietários rurais e/ou comunidades tradicionais com o projeto praticamente pronto apresentando o PSA como uma alternativa para esses atores. Porém, na maioria das vezes, salvo raras exceções, esses atores não são envolvidos na parte fundamental do projeto que é o seu planejamento, para contribuir na tomada de decisão da estratégia a ser adotada e na metodologia geral do projeto. Isso é uma prática básica nos PSAs comunitários do Peru, Venezuela, Costa Rica, México e Bolívia, mas muito pouco praticado no Brasil. O Programa Bolsa Floresta da Fundação Amazonas Sustentável (FAS) e o Projeto de Carbono com a comunidade indígena Suruí, são experiências que consideram o planejamento participativo na sua metodologia e que alcançaram excelentes resultados nesse sentido.

Por fim e o mais importante, é necessário ter clareza de que o PSA não é a solução para tudo e que não se aplica em todos os lugares e situações. Há casos em que o PSA não contribuirá para a solução do problema, pelo contrário, se implantado ele pode agravar um problema já existente, resultando em maiores desmatamentos e degradação socioambiental. Nesse sentido, também é importante ter clareza de que em determinadas situações o PSA é algo imediato e de curto prazo, para frear uma prática predatória, enquanto que em outras situações o PSA deve ser planejado em médio e longo prazo, fortalecendo a relação entre usuário-pagador e provedor-recebedor.

De qualquer maneira, o PSA tem se mostrado como uma excelente ferramenta de gestão territorial, agregando aliados e abrindo o diálogo entre diferentes setores da sociedade. Por se tratar de uma ferramenta multidisciplinar, talvez seja ela o princípio do caminho para um desenvolvimento sustentável viável que aproxima a população urbana da rural e comunidades tradicionais, pela relação que os serviços ambientais criam entre esses atores. Nesse sentido, o pagamento em dinheiro não se torna a principal estrutura do esquema, mas sim, a relação entre os atores e o reconhecimento de boas práticas que favorecem a toda a sociedade.

Carlos Augusto Krieck é biólogo pela Universidade Regional de Blumenau e Mestre em Ecologia e Conservação pela Universidade Federal do Paraná. Atualmente é Assessor para Serviços Ambientais e Biodiversidade do Vitae Civilis Instituto para o Desenvolvimento, Meio Ambiente e Paz.

\section{Referências bibliográficas}

ANDRADE, J.P.S. (2007) A implantação do pagamento por serviços ecossistêmicos no território Portal da Amazônia; uma análise econômica-ecológica. Campinas: IE/Unicamp. Dissertação de Mestrado. 2007.

ASLAM, Abid e SZCZUKA, Julia (Editores) et al. Situação Mundial da Infância. New York: United Nations Children's Fund (UNICEF) - Fevereiro de 2012 - Disponível em http://www.unicef.pt/18/Relatorio_SituacaoInfancia2012.pdf - Acessado em 31/03/2013

BRASIL-Inventário Brasileiro de Emissões - Disponível em: http://www.brasil.gov.br/cop/ panorama/o-que-o-brasil-esta- -fazendo/inventario-de-emissoes

- Acessado em 31/03/2013

BRASIL - ONU aprova em Nagoyaprotocolo que garante repartição dos benefícios pelo uso da biodiversidade. 29/10/2010

Disponível em: http:// www.brasil.gov.br/noticias/ arquivos/2010/10/29/onu-aprova-em-nagoya-protocolo-que-garante-reparticao-dos-beneficios-pelo-uso-da-biodiversidade - Acessado em 3/04/2013

BURKHARD, Benjamin. Solutions for sustaining natural capital and ecosystem services. Ecological Indicators 21 (2012) 1-6

CBD - Secretariat of the Convention on Biological Diversity
(2010) Global Biodiversity outlook 3, Montréal. URL: http:// www.cbd.int/ doc/publications/ gbo/gbo3-final-en.pdf. Apud: UNITED NATIONS ENVIRONMENT PROGRAMME (UNEP) - The Economics of Ecosystems and Biodiversity. For Business (TEEB). 2010.

CECHIN, Andrei. A natureza como limite da economia:a contribuição de Nicholas Georgescu-Roegen. São Paulo: Editoras Senac/ Edusp, 2010. 264 p.

CHOMITZ, K. M.; BRENES, E; CONSTANTINO, L. Financing environmental services: the Costa Rican experience and its implications. The Science of The Total 
Environment, v. 240, p. 157-169, 1999. Apud:WUNDER, Sven (Coord.), BÖRNER, Jan,PEREIRA, Ligia, TITO, Marcos Rügnitz. Pagamentos por serviços ambientais: perspectivas para a Amazônia Legal. Brasília: MMA, 2008. (Série Estudos, 10).

COSTA, F.A. "Balanço de Carbono e Economia Local: um ensaio sobre a região crítica da Amazônia usando Contas Sociais Alfa (CSa) . Belém: Papers da NAEA/UFPa. No. 216. Apud: ROMEIRO, Ademar Ribeiro et. al. Economia do Meio Ambiente. In: NOVION, Henry, VALLE, Raul do. (Orgs.) É pagando que se preserva?Subsídios para políticas públicas de compensação por serviços ambientais. São Paulo: Instituto Socioambiental, 2009. P. 43-86.

COSTANZA, Robert. Economia Ecológica: uma agenda de pesquisa. In: MAY, Peter Herman, SERÔA DA MOTTA, Ronaldo. Valorando a natureza: análise econômica para o desenvolvimento sustentável. Rio de Janeiro: Ed. Campus, 1994.

COSTANZA, Robert et al. 1997: "The Value of the World's Ecosystem Services and Natural Capital", Nature. 387:253-260, 15 de maio, 1997.

COSTANZA et al. Developing an Integrated History and future of People on Earth (IHOPE). Current Opinion in Environmental Sustainability 2012, 4:106-114

DALY, H., FARLEY, J. Economia Ecológica. Princípios e Aplicações. Lisboa: Instituto Piaget, 2004. 530p.

FARLEY, J, COSTANZA, R. Payments for ecosystem services: From local to global. Ecological Economics. 69 (2010) 20602068

FASIABEN, M C R.; ANDRADE, D C ; REYDON, B P ; GARCIA, J R ; ROMEIRO, A R (2009). Estimativa de aporte de recursos para um sistema de pagamento por serviços ambientais na floresta amazônica brasileira. Ambiente e Sociedade (Campinas), v. 12, p. 0622, 2009

FONSECA, Vera Lúcia Imperatriz. "Os serviços dos ecossistemas". Revista digital pré-Univesp. São Paulo: 3. Agosto/2010. disponível em: http://www.univesp.ensinosuperior.sp.gov.br/ preunivesp/346/os-servi-os-dos-ecossistemas.html - Acessado em 30/03/2013

FREITAS, Analuce, CAMPHORA, Ana Lucia. Contribuições dos Estados Brasileiros para a Conservação da Biodiversidade: diagnóstico das Unidades de Conservação Estaduais - Rio de Janeiro, Minas Gerais, Espírito santo, Paraná e Rio Grande do Sul. Brasília: TNC. Setembro de 2009.

INTERGOVERNMENTAL PANEL ON CLIMATE CHANGE (IPCC)"Quarto Relatório de Avaliação do IPCC - Mudança do Clima”. 2007 - Disponível em: - http://www. mct.gov.br/index.php/content/ view/50401.html - Acessado em 11/09/11

IPEA. Relatório de Pesquisa sobre Pagamento por Serviços Ambientais Urbanos para Gestão de Resíduos Sólidos. Brasília: IPEA, 2010. Disponível em: http://www.mds.gov.br/acesso-a-informacao/orgaoscolegiados/ orgaos-em-destaque/ciisc/arquivos/Relatorio\%20PSAU.pdf/view. Acessado em 31/03/13

KUMAR, Pushpam et al. The economics of ecosystem services: from local analysis to national policies. Current Opinion in Environmental Sustainability 2013 , 2013, 5:78-86

LANDELL-MILLS, N. e PORRAS, I.T. Silver bullet or fools' gold? A global review of markets for Forest environmental services and their impact on the poor. Interna- tional Institute for Environment and Development (IIED), London, 2002. Apud:HERCOWITZ, Marcelo, WHATELY Marussia. Serviços Ambientais: conhecer, valorizar e cuidar: Subsídios para a proteção dos mananciais de São Paulo. São Paulo: Instituto Socioambiental, 2008.

MATTOS, Luciano, HERCOWITZ, Marcelo, SOUZA, Raquel Pereira de. "Estudos de casos sobre serviços ambientais". In: NOVION, Henry, VALLE, Raul do. (Orgs.) É pagando que se preserva? Subsídios para políticas públicas de compensação por serviços ambientais. São Paulo: Instituto Socioambiental, 2009.

MATTOS, Luciano, HERCOWITZ, Marcelo. "Políticas Públicas". In: NOVION, Henry, VALLE, Raul do. (Orgs.) É pagando que se preserva? Subsídios para políticas públicas de compensação por serviços ambientais. São Paulo: Instituto Socioambiental, 2009.

METZGER, Jean Paul. Conservação Ecológica - Biogeografia de ilhas e metapopulações. Apresentação em Power Point.http:// eco.ib.usp.br/lepac/eco_humana/ conservacao_ilhas_metapop.pdf Acessado em 1/04/2013

MMA-Dados sobre a Biodiversidade Brasileira (2013) - http:// www.mma.gov.br/biodiversidade/biodiversidade-brasileira Acessado em 29/03/2013

MCT - Programa de Grande Escala da Biosfera-Atmosfera na Amazônia (2013) - Disponível em: http://lba.inpa.gov.br/ $\mathrm{lba} / \mathrm{p}=$ oportunidade $\& \mathrm{t}=0 \& \mathrm{~s}=5$ $\& \mathrm{lg}=\& o p=2460$ - Acessado em 29/03/2013

METZGER, Jean Paul. "Uma visão global da fragmentação". Revista Página 22. São Paulo: 5:48-51. Fevereiro/2007.

NOVION, Henry, VALLE, Raul do. (Orgs.) É pagando que se pre- 
serva?: subsídios para políticas públicas de compensação por serviços ambientais. São Paulo: Instituto Socioambiental, 2009.

OLIVEIRA, Luiz Rodrigues de. Programa de Desenvolvimento Socioambiental da Produção Familiar Rural. Apresentação de Power Point apresentado no Seminário Pagamento por Serviços Ambientais. Promovido pela Viex América em São Paulo (SP), em 6/10/2009.

REYDON, Bastiaan Philip. O desmatamento da floresta amazônica: causas e soluções. In: GRAMKOW, Camila L., PRADO, Paulo Gustavo (Orgs.). Política Ambiental - No. 8 - Economia Verde - Desafios e Oportunidades. Belo Horizonte: Conservação Ambiental, 2011.

REYDON, Bastiaan Philip. Mecanismos para a valorização da floresta. Anais do $17^{\circ}$. Congresso Direito Por Um Planeta Verde. 2011.

ROMEIRO, Ademar Ribeiro. "Economia ou economia política da sustentabilidade". In: LUSTOSA, Maria Cecília, MAY, Peter H., VINHA, Valéria da (orgs.). Economia do meio ambiente: teoria e prática. Rio de Janeiro: Ed. Elsevier, 2003.

SOARES-FILHO, B. S. et. al. "Modelling conservation in the Amazon basin" Nature, v. 440, p. 520-523, 2006. Apud: WUNDER, Sven (Coord.), BÖRNER, Jan,PEREIRA, Ligia, TITO, Marcos Rügnitz. Pagamentos por serviços ambientais: perspectivas para a Amazônia Legal. Brasília: MMA, 2008. (Série Estudos, 10).
SANTOS, Priscilla; BRITO, Brenda; MASCHIETTO, Fernanda; OSÓRIO, Guarany; MONZONI, Mário. (Orgs). Marco regulatório sobre pagamento por serviços ambientais no Brasil/Belém, PA: IMAZON; FGV. CVces, 2012.

SHIKI, S. Proambiente. Payment for Ecosystem Services: from Local to Global. 2007.

TURNER, W. R. et al. "Global conservation of biodiversity and ecosystem services". Bioscience, v. 57, p. 868 2007. Apud: WUNDER, Sven (Coord.), BÖRNER, Jan,PEREIRA, Ligia, TITO, Marcos Rügnitz. Pagamentos por serviços ambientais: perspectivas para a Amazônia Legal. Brasília: MMA, 2008. (Série Estudos, 10).

UNITED NATIONS (UN) -Millennium Ecosystem Assessment.2005.

Disponivel emhttp://www. millenniumassessment.org/ en/index.html - Acessado em 1/04/2013.

UNITED NATIONS (UN) - UNITED NATIONS ENVIRONMENT PROGRAMME (UNEP) - The Economics of Ecosystems and Biodiversity (TEEB) - For Business.2010.Disponível em: http:// www.teebweb.org/- Acessado em1/04/2013.

VALLE, Raul do. (Orgs.) É pagando que se preserva?Subsídios para políticas públicas de compensação por serviços ambientais. São Paulo: Instituto Socioambiental, 2009. P. 43-86.

VIANA, Virgílio M. Sustainable Development in Practice: Lessons Learned from Amazonas. London:
International Institute for Environment and Development, 2010.

Disponível em: http://pubs.iied. org/pdfs/17508IIED.pdf - Acessado em3/04/2013.

VIVAN, Jorge Luiz. Experiências Brasileiras de Pagamentos de Serviços Ambientais em Perspectiva Comparada às Estratégias Internacionais. Estudo 2 - Segundo Relatório. Brasília: Diálogo Setorial Brasil-União Européia, 2012.

YOUNG, Carlos Frickmann, PAVESE, Helen Boniatti, MEDEIROS, Rodrigo (Orgs.). Contribuição das unidades de conservação brasileiras para a economia nacional: Sumário Executivo. Brasília: UNEP-WCMC, 2011.

WUNDER, Sven. "Payments for environmental services: some nuts and bolts". CIFOR OccasionalPaper, n. 42, 2005. Apud: WUNDER, Sven (Coord.), PEREIRA, BÖRNER, Jan, Ligia, TITO, Marcos Rügnitz. Pagamentos por serviços ambientais: perspectivas para a Amazônia Legal. Brasília: MMA, 2008. (Série Estudos, 10).

WUNDER, Sven (Coord.), BÖRNER, Jan,PEREIRA, Ligia, TITO, Marcos Rügnitz. Pagamentos por serviços ambientais: perspectivas para a Amazônia Legal. Brasília: MMA, 2008. (Série Estudos, 10).

Sites

- Comunidade de Aprendizagem PSA - http://www.aprendizagempsa.org.br/

- Rios Voadores - www.riosvoadores.com.br

Autores: Célia Massako Onishi, Administradora de Empresas pela Faculdade de Economia e Administração da USP, Mestranda em Desenvolvimento Econômico pelo Instituto de Economia da Unicamp e Coordenadora de Projetos do Instituto Samuel Murgel Branco. Endereço eletrônico: celia.onishi@ismb.org.br; Rosana Filomena Vazoller, Bióloga, Conselheira do Instituto Samuel Murgel Branco (http://lattes.cnpq.br/0357556525507074); Bastiaan Philip Reydon, Professor livre docente do Núcleo de Economia Agrícola e Ambiental do Instituto de Economia da Universidade Estadual de Campinas (NEA/IE/Unicamp), assessor de Sustentabilidade da Agência de Inovação - Unicamp e consultor do Banco Internacional de Reconstrução e Desenvolvimento (Banco Mundial) e da FAO. Endereço eletrônico: basrey@eco.unicamp.br 